\title{
Social Justice Games: Building an Escape Room on Elder Abuse through Participatory Action Research
}

\author{
Constance Lafontaine ${ }^{1} \cdot$ Kim Sawchuk $^{1} \cdot$ Scott DeJong $^{1}$
}

Published online: 30 April 2020

(c) The Author(s) 2020

\begin{abstract}
This paper discusses the creation of an escape room on older adult mistreatment (or elder abuse). The game, titled Sandra's Keys, invited players to engage with the story of a fictional older woman dealing with a situation of abuse through a series puzzles. The escape room sought to bring players into a conversation about the different forms of elder abuse, and to give them a greater understanding of their role as bystanders and of the potential ways to intervene. The escape room game was co-designed by researchers, a group of older adults activists in Montreal and a social worker. This paper focuses on how we made this game and the methodological principles and values behind the design process. This design process is grounded in Participatory Action Research and is inspired by the writings of radical theatre activist Augusto Boal. One of its aims was to consolidate long standing relationships between the members of the design team around a common social justice goal. We map out the potential of games to become tools in the 'arsenal' of community-based activism and to playfully contradict dominant societal norms related to age. Finally, we introduce the term 'social justice game' to assert the connections between activism, social justice and games studies.
\end{abstract}

\section{Introduction}

Escape rooms are a sub-genre of immersive 'analog' problem-solving games that have become popular over the past decade with younger adults (Boshci 2016; Nicholson 2016). Escape rooms can engage with a variety of themes, and commonly entail escaping from a place, like a prison, or investigating a crime or mystery

Constance Lafontaine

constance.lafontaine@concordia.ca

Kim Sawchuk

kim.sawchuk@concordia.ca

Scott DeJong

scottbdejong@gmail.com

1 Concordia University, Montreal, Canada 
(Nicholson 2015, p. 15). Escape rooms usually are experienced in teams; groups of players are tasked with solving thematically rendered puzzles and riddles within a specific time limit.

In 2019, we collaborated with a group of older adults in Montreal to create an escape room on the topic of elder abuse or as it is known in our local context 'older adult mistreatment'. Respecting Elders: Communities Against Abuse (RECAA) is a collective of older adult activists from Montreal tackling elder abuse and the specific challenges faced by seniors who have recently immigrated to Québec and/or who are from racialized backgrounds. The members of RECAA develop and perform non-verbal short skits, using activist techniques adapted from Augusto Boal's Theatre of the Oppressed, such as forum theatre. RECAA's goal is to raise awareness of elder abuse within the various cultural and linguistic communities in Montreal who are often forgotten or marginalized from government services (Walsh et al. 2007). We also collaborated with a social worker and social gerontologist from CREGÉS (Centre de recherche et d'expertise en gérontologie sociale). RECAA and CREGÉS joined into the process of the game's development, not only as consultants but as meaningful partners with valuable expertise and ideas to help guide workshops, meetings, playtests, and debriefs.

In this paper, we focus on the challenges and strategies co-developed to build an escape room based on elder abuse, which we titled Sandra's Keys. Reflecting upon our design and implementation of the game led us to conceptualize Sandra's Keys as a social justice game. Social justice games, as we suggest, are a subgenre of "social impact games" (Grace 2019; LaPensée 2014; Ruggiero 2015; Swain 2007), part of the Games for Change movement (LaPensée).

We highlight how our commitment to participatory action research (PAR) and the deep knowledge of forum theatre by our community partners informed our design approach, decision-making process, implementation, and the gameplay elements. Within PAR, we find a method for creating a social justice game that remains faithful to community objectives. We emphasize the points of convergence between forum theatre and our escape room to assert the potential of the format as a tool that can incorporate the social justice perspective embedded in our partner's mandate. Finally, we explain how Sandra's Keys challenges and contradicts dominant societal norms related to age.

\section{Context: Elder Abuse in Canada}

Elder abuse has long been identified as a hidden problem that is seldom reported (Rodríguez et al. 2006), with some studies suggesting that incidences of mistreatment are close to 24 times the reported rates (Ejaz et al. 2017). There are multiple factors that account for low reporting rates (see Ejaz et al. 2017), such as a lack of awareness and confusion over exactly what constitutes abuse (The National Seniors Council 2007, p.5).

Researchers and practitioners emphasize the need for improvements in education, training and awareness (Joshi and Flaherty 2005; McCool et al. 2009; Dehart et al. 2009; Podnieks and Thomas 2017). While these needs are well-established 
in the literature, there remains little published research on the initiatives, tools and approaches that are likely to broach elder abuse with the general public and elicit action. Even fewer initiatives focus on reaching younger demographics (see initiatives by the British Columbia-based Canadian Network for the Prevention of Elder Abuse (CNPEA). Researchers often call for the implementation of cross-sectoral and multi-disciplinary initiatives on elder abuse to engage the public (Faccinetti 2004) and emphasize the need to include older adults in strategies for awareness (Harbinson 1999).

Since 2011, we have been collaborating in digital media-making projects with RECAA. As we have learned from RECAA over the years, problems tied to elder abuse may be amplified for those who have recently immigrated to Canada. Older adults in these positions may not have French or English as a first language and have difficulty accessing resources and services (Lee et al. 2014; Walsh et al. 2007), they may experience problems due to sponsorship programs that can make them reliant on their children, and they may hold experiences that make them suspicious of authorities (Guruge et al. 2019; Sawchuk 2013). In the context of Québec, the intersections of race, class, age, language, and gender have become ever more prominent with the introduction of government legislation that marginalize many members of these communities from the hegemonic culture even further (notably, Bill 21's ban on religious symbols in the workplace for public service employees and authority figures) (Patrick et al. 2019).

Given these challenges, the questions that arise for us include: What kind of education and communication initiatives are needed to engage and inform the public on this topic? What kind of event or activity could be created to meaningfully include community partners? How should we represent our main protagonist and the escape room environment?

\section{Literature Review}

\subsection{Aging and Games}

Escape rooms can be understood as "live-action team-based games where players discover clues, solve puzzles, and accomplish tasks in one or more rooms in order to accomplish a specific goal (usually escaping from the room) in a limited amount of time" (Nicholson 2016, p. 1). Since 2017, educational iterations of escape rooms have emerged (Adams et al. 2018) for teaching topics like medical diagnostics (Eukel et al. 2017), pharmacology (Hermanns et al. 2017) and physics (Vörös and Sárközi 2017).

More recently, escape rooms have been used to broach difficult social issues, such as homelessness (CBC 2017) or young people/teenagers who experience violence while dating (La Presse Canadienne 2018). Despite these initiatives, there has been limited attention or analyses by academics on how or if the escape room format can raise public awareness of serious social issues. Existing literature situates escape games as effective mediums for knowledge dissemination, typically explored within undergraduate classroom settings (Eukel et al. 2017) and millennial age groups 
(Lama 2018). Adams et al. (2018) argue that escape rooms have a particular ability to engage learners through their immersive environments, suggesting that they may empower participants through an active involvement in gameplay.

There is an emergent literature that takes age into account in game design (De Schutter 2019; Loos 2014; Marston 2013; Osmanovic and Pecchioni 2016) and some key research exploring representations of age and aging within games or older users of games (Blocker et al. 2014; Sayago 2019). Bob De Schutter, for one, has explored older games. His recent work, Brukel, incorporates the stories of older audiences into a game's narrative. Consalvo and Begy (2015) have engaged with the fan-base of players over 35 to the game Faunasphere. Within education, the work of Romero and Lille (2017) examines the potential of game-based learning throughout the life-span and highlights the value of design scenarios that allow older adults and children to come together and explore their creativity in the design process.

Within game studies, there is a growing literature on serious games, social impact play and social impact games (Grace 2019, pp. 31-32). In a recent comprehensive discussion of social impact games, Lindsay Grace notes that social impact games have numerous definitions and encompass a wide variety of practices. Social impact games are often discussed alongside the broader category of serious games (LaPensée 2014; Grace 2019). Overall, serious games strive to "engage the user and contribute to the achievement of predefined objectives" (Susi et al. 2007, p. 5) and promote thoughtfulness in storytelling (Lugmayr et al. 2017). Social impact games have more precise goals of informing, training and educating to create social change (Grace 2019).

For Elizabeth LaPensée (2014), social impact games can create awareness around a specific issue, educate players, change the attitudes and/or behaviors of players, and/or promote activism and social engagement. In her cogent discussion of serious games and social impact games, LaPensée (2014) suggests that some social impact games are connected to the 'Games for Change' movement. Her research adds an important critical dimension to the discussion of social impact games, as she distinguishes social impact games from impact games that are, for example, tied to commercial or corporate interests.

Dana Ruggerio, who wrote one of the first articles on social impact games, emphasizes the values of civic engagement, arguing that such games can involve "helping or guiding other players, thinking about moral or ethical issues, learning about a problem in a society, and learning about social issues" (Ruggiero 2015, p. 597). Categorizing games always poses a challenge, however building from the framework of social impact games, as articulated by Ruggerio and LaPensée, this project reflects on our incorporation of activist methodologies into design, creating what we describe as a 'social justice game'.

\subsection{Social Justice, Pedagogies of the Oppressed and Co-Design}

Social justice is a semiotically robust philosophical term with a longstanding history and set of positions, from Aristotle to Rawls to more recent feminist and post-colonial discussions (Fraser 1999). As feminist philosopher and political 
theorist Nancy Fraser (Ibid.) argues, social justice typically embodies two sorts of claims: first, for the redistribution of resources to achieve greater equality and fairness; and second, for the recognition of differences in identities. In terms of the legal and policy literature, the concept of social justice highlights the need to attain fairness beyond individual justice. Social justice issues examine the systemic and structural arrangements to impart equity as a political and social value (Baldry and McCausland 2009, p. 7).

Within the legacy of social justice Paolo Freire and Augusto Boal have contributed to the philosophies of education (Friere) and theatre (Boal) to promote equality, fairness and recognition (Freire and Macedo 2000; Boal 2005). This legacy has informed the ethical stance of the members of RECAA (Sawchuk and Lafontaine 2018). For Freire and Macedo, the goal of education is not simply to provide skills to students, which he has called the banking approach to education, but to interest students in the processes of learning to challenge dominant systems and relations of power. This is problem-solving education. As they write in Pedagogy of the Oppressed:

Whereas banking education anesthetizes and inhibits creative power, problem-solving education involves a constant unveiling of reality. The former attempts to maintain the submission of consciousness; the latter strives for the emergence of consciousness as critical intervention in reality (Freire and Macedo 2000, p. 81)

Written in the context of post-colonial struggles in Latin America and Brazil in the 1960s, the authors advocated for students to be active participants in the processes of education.

Central to Freire and Macedo's understanding of power and oppression is his use of the preposition "with". A pedagogy of the oppressed:

Must be forged with, not for, the oppressed (be they individuals or whole peoples) in the incessant struggle to regain their humanity. This pedagogy makes oppression and its causes objects of reflection by the oppressed (2000, p. 25)

A contemporary of Freire's, Boal (2005) builds on this philosophy in Theatre of the Oppressed, which provides an activist and participatory set of actions, including exercises and games, meant to facilitate conversation and lead to what Freire and Macedo call "conscientization": the process of becoming aware. Alongside Freire and Boal's influence on RECAA, and thus our philosophy of game design, Freirian goals have a strong connection to the values embedded in participatory action research (PAR), critical in our approach to projects of cocreation and co-design with older adults at ACT.

PAR approaches seek "to understand and improve the world by changing it" (Baum et al. 2006). The deployment of PAR methods that incorporate our feminist interpretation of the values of Freierian pedagogy is at the crux of our approach to the co-design of games. The idea of co-design is commensurate with this approach by engaging across sectors within a community, and in the case of 
inter-generational co-design, bringing the experiences and knowledge of diverse age groups to bear on a project (Xie et al. 2012; Romero and Lille 2017). Within the field of game studies, Khaled et al. (2014) consider participatory co-design as a critical aspect of serious game design. The process of design allows participants to connect existing knowledge to the overall content and design process of the final topic (Khaled et al. 2014).

\section{Methodology}

\subsection{Implementing our Approach}

When we approached our collaborators from RECAA and CREGÉS with the idea of creating an escape room relating to elder abuse, our would-be collaborators had not previously heard of escape rooms and were subsequently hesitant about the format. As such, our first activity was to play an escape room game together to determine if they thought the idea would be feasible and commensurate with their approach to dealing with elder abuse. This experience highlighted the discernable differences between the objectives embedded in a commercial for-profit escape room with a permanent setting, and those of an escape room that would be of a short duration, free to the public, and with the limited financial resources of academics and notfor-profit community-based activists. After playing the commercial escape room together, the buy-into the project was immediate. RECAA was drawn to the 'theatricality' of the format and recognized that it mimicked many of the elements of forum theatre including: role playing, the use of an implied narrative; and the use of props.

We followed up on this initial encounter by asking the team to reflect on their play experience and to brainstorm over a three-week period. Afterwards, we facilitated two workshops held a month-and-a-half apart. The first workshop focused on the potential scope of the game. We discussed a range of ideas for the puzzles and the game narrative and considered potential concerns. This led to a second workshop on the process of structuring a debrief session and how this would differ from traditional post-game interviews or surveys. RECAA's insights from forum theatre were again invaluable and led us to make the decision that we needed to incorporate a debrief as part of the experience. Ideally, this would happen in teams: one member of RECAA and one student facilitator would lead a post-game discussion with the players.

We designed and implemented rough iterations of the games for playtesting. We held three different testing sessions, inviting our design team to play, give feedback, and subsequently to adjust the game accordingly. We reached out to our network of older adults, students and academics, and beyond, and the playtests included external members from outside of the team, such as fellow game designers at Concordia University and other older adults. Playtest sessions were held over the course of a week, during which participants either played the game or were walked through the game experience and asked to share comments on the game's design, focusing on environment, narrative, and player accessibility. The playtests engaged over twentyfive individuals. After the first two playtests, which focused on the game and play 
experience, the final playtest session had students and RECAA members facilitate debriefs together providing training on how to deal with discussions on elder abuse.

Sandra's Keys was implemented for 2 weeks in the context of a public conference associated with "aging in the city". During this time, members of RECAA, alongside students, engaged with the larger public and ran post-game debriefs that embedded forum theatre practices used by RECAA to generate conversation with participants. As such, players were asked to book an hour-and-a-half long play session, each involving 30-min of gameplay followed by a debrief that would last between 30 min and an hour. After a two-week implementation phase, we emailed everyone who worked on the project to respond to a series of open-ended questions about their participation in the project, asking them to reflect on the design and implementation of the escape room. Additionally, we conducted a face-to-face meeting with our collaborators from RECAA and CREGÉS, during which we discussed next steps, including tweaks to the game design and future iterations.

\subsection{The Game}

Sandra's Keys is centred on the life of a fictional older woman, Sandra, who is experiencing abuse from members of her social circle, including a hired caregiver and her daughter. The goal is to retrieve Sandra's keys, which are hidden somewhere in the room. Players are invited to enter Sandra's 'apartment'; a room furnished like a studio apartment. Before entering, players are told by the 'landlord' (the game facilitator) that they are Sandra's trusted friends. Upon entering the apartment, players are confronted with overt and subtle clues in the environment that point to occurrences of abuse. As they search for the hidden keys, players interact with the space and solve four themed puzzles that reveal four different forms of mistreatment: the denial of rights, financial abuse, psychological abuse, and physical abuse. At the end, players are required to participate in a half-hour debrief session with trained facilitators to ensure their emotional well-being, discuss their experience of the game play and Sandra's dilemma.

\section{Discussion of Results: PAR and Forum Theatre and a Method to Implement a Social Justice Game}

\subsection{Social Justice Engagement Through a PAR Approach}

PAR pursues the emancipatory, critical, and liberatory goal of a more democratic and just society (Hearn et al. 2009; Reason and Bradbury 2008). Our commitment to PAR, as it became incorporated into the game, is inspired by four guiding principles. First, we conduct research with seniors, rather than research on this population. Within this perspective, and drawing upon the work of Virginia Eubanks, we emphasize understanding the heterogeneity of seniors and their position as "assetbearing" rather than deficient or needy (Eubanks 2012). Second, we choose to work with older adults who have been historically marginalized in traditional approaches 
to research. Many of our projects involve working with seniors who find themselves in situations of precarity because of socio-economics, immigration status, language ability vis-à-vis the dominant languages of French and English, or gender. Third, our commitment to PAR brings us to work outside of our university and pushes us to open its doors to community groups. Finally, our long-standing commitment to PAR has entailed building long-term relationships with partners like RECAA. Collaborative projects with partners foreground reciprocity and exchange, while emphasizing an attention to process and not just outcomes. Crucial to these relationships is a shared understanding of our respective goals, a recognition of how these converge around social justice issues, and a mutual trust that has been built over the years (Grenier and Sawchuk 2017; Lafontaine and Sawchuk 2018, Sawchuk and Lafontaine 2018).

It is in fact our longstanding partnership with RECAA and a desire to address elder abuse together that inspired Sandra's Keys. By adopting a co-design process grounded in a PAR approach, Sandra's Keys built upon and strengthened an existing community connection, grounded in a shared concern for social justice and a commitment to activism. In the context of a project like Sandra's Keys, where the task 'to gamify' an issue like elder abuse is delicate and where expertise from partners is crucial, we recognized the need to engage our community partners but as well the need to study, in more depth, the topic of elder abuse and to make a commitment to working with these partners beyond the duration of this particular project. In addition, an effective approach to social justice games is aided by research practices that are, at their core, attentive to relations of power inequalities between partners, and the ways that this inequality can operate systemically and structurally. The unique history of collaboration that we had with this community organization, combined with our commitment to doing our homework on the topic of elder abuse, opened up an opportunity to adopt a game development approach that combines PAR and intergenerational co-design commensurate with our intellectual values and those of our community participants.

\subsection{Re-imagining Activist Practices: From Forum Theatre to the Escape Room}

In game studies, there are but a few articles that draw the connection between forum theatre and game studies. This includes Frasca's (2001) discussion of the potential of "Videogames of the Oppressed", which speculates on how this practice might be integrated into a digital game. A more recent article by Pötzsch, discusses forum theatre and other radical theatrical practices as means to understand digital games, however, it primarily deals with aesthetics, without delving into any particular games or game design. Shyba (2008) develops the concept of 'gamathurgy' and examines the potential of both theatre and (video)games as a mode for rehearsing for the future.

In what follows, we establish some of the connection points between the escape room experience we designed and forum theatre to support the assertion that the escape room can provide a fertile ground to deploy and re-imagine long standing activist practices such as those of forum theatre and to deal with difficult topics, like 
older adult mistreatment. We describe this connection in terms of a set of methodological steps or procedures for creating a social justice game, deploying the principles of forum theatre.

\subsubsection{Dialogue and Rehearsing for the 'Real World'}

Key to forum theatre is prioritizing discussions between people over seeking specific outcomes or prescriptive solutions. In Boal's words "it is more important to achieve a good debate than a good solution" (Boal 2002, p. 259). As we developed the game with our partners, people raised the dual concerns of (1) taking care not to frame abuse as something that can be easily "escaped" and (2) navigating the delicate balance of gamifying but not trivializing a serious issue. For these reasons, we decided that the escape room experience required a facilitated debrief component as a central element of Sandra's Keys. The debrief helped contextualize the space and connect the puzzles more explicitly to the experience of elder abuse. It moved the escape room experience from being entirely 'outcome focussed,' as is the case for commercial or entertainment-based escape rooms.

Through the debrief, players would discuss not only their experience in the room, but tell stories from their lives, and identify potential ways they could imagine themselves taking as bystanders. The idea of the bystander is a key notion in the literature on elder abuse, as it emphasizes that one should not intervene or act for someone: you need to listen, name the issue and provide access to professional resources (It's not right 2020).

The escape room was designed to position the players as trusted friends and thus conscript them into the fictional social world of Sandra. They were given the chance to consider how they might act in a given situation where they encountered signs of abuse. Just as in forum theatre, the experience of the escape room sought to give players the freedom to embody a role for a brief amount of time and to devise possible means to engage with a similar real-world scenario.

\subsubsection{Acknowledging the Complexities of Oppression}

A key tenet of forum theatre is to address the everyday conundrums of oppression, and the often nuanced and convoluted ways in which people exert power over others in given contexts (Boal 2005). These complex experiences are abundant in situations of elder abuse, where oppression often takes place within the confines of the home and family relations. As we found, the escape room provides a rich setting to engage with such complexities because it allows for different implied protagonists from Sandra's social circle to make appearances through the clues and puzzles left behind. For instance, an audio-tape that contains the following phone message from Sandra's daughter offers hints on the nature of their relationship:

Hey Mom,

Sorry that I missed our last visit. I know that you enjoy seeing Mr. Plant, Mrs. Rose, and Mrs. Cardinal at bingo on Saturdays but I don't want to drive you there anymore. It's exhausting to get you into the car with your mobility issues. 
I'm not sure when it became my job to taxi you around. The bus stop is only a thirty minute walk from your apartment and the exercise would probably do you some good and if you're not feeling up to getting yourself there, just stay home. Let's try to see this as an opportunity to try some healthier habits. Ohlook at the time - I gotta run. Love you! Bye!

On one hand, the message indicates a scenario of portential psychological abuse. The daughter makes Sandra feel guilty for taking too much of her time and threatens to further narrow her social circle. Most players recognized the message as a sign of a situation of abuse. However, six participants also recognized that the voice on the tape sounded like that of a stressed daughter with a lot on her plate, who is forced to juggle multiple responsibilities. As such, the depicted scenario indicates that abuse can be intentional or unintentional and that different positionalities within the complexity of interpersonal relations needs to be considered. This puzzle also highlighted how some situations of abuse can be difficult to ascertain due to systemic and structural conditions related to gendered expectations of care, where daughters are often put in a situation of being care providers (unpaid usually) in families.

By incorporating these complex situations, which are difficult to solve and are related to structural and systemic power dynamics in Canadian society, the escape room experience challenged the idea of 'magic' pill solutions to a problem, such as elder abuse (Boal 2002), something that the forum theatre approach also rejects. Magic pill solutions are, in effect, responses to the situation that are highly unlikely to be available to individuals in real life and they are unlikely to provide a pathway to resolve the problem at hand.

\subsubsection{From the Particular to the Collective}

Boal remarks that forum theatre begins with the narrative of a single person, which provides an entryway into a thematic. Yet Boal stresses the importance to move beyond the singular, and to "pluralize" the experience $(1995, \mathrm{p} .45)$. The story of Sandra provides a way into a subject matter, but the debrief and discussion between players allows for participants to understand the commonality of the narrative depicted, and to link Sandra's story to the broader issue of elder abuse. As such, the story is given a symbolic dimension that allows the players to recognize and better understand other instances of abuse that may present themselves in their own lives. In his comprehensive book on social impact games, Lindsay Grace stresses the need for games, no matter what the topic, to be a game and advocates for play as an important dimension of human activity, and occasion for learning and problemsolving together (Grace 2019).

Like forum theatre, escape rooms encourage collaboration, using a game to facilitate participant playfulness, engagement, and creativity around an issue. Although the goal in the room is specific-find the keys-it puts play at the centre of collectively devising strategies for change. Boal's approach to games sees them as activities that become a shared experience between people. Games, such as practices of forum theatre, "are a dialogue, they require an interlocutor. They are extroversion" (Boal 2002, p. 48). In considering accessibility, for example, we tried to create an 
environment that would be as inclusive and welcoming to people of diverse ages and abilities as we could within the constraints of the escape room genre and in the context of a temporary space. We left enough room for people who use wheelchairs to navigate the space and made sure not to hide items too low to the ground. We ensured that we had good lighting and multiple spaces for participants to sit.

\subsubsection{Scripts, Rules and Structure to Open Up a Space for Discussion}

Forum theatre relies on a set of rules, which are communicated and applied by a 'joker'. It is the joker's responsibility to enforce the structure of the game, to keep people on topic and to foster connections between the performers and the audience, who in the language of forum theatre are called 'spect-actors' to signal the fluidity of roles (Boal 2005). In the case of our escape room, we relied on a similar character as the joker: a facilitator who welcomed players, introduced the experience as an escape room on elder abuse, explained the rules of the game, presented the narrative, acted as the landlord and, importantly, conducted the debrief and encouraged discussion among participants. In our case, the facilitators were members of RECAA or of the research team as well as graduate students who had undergone basic training on being a responsible 'bystander' in situations where elder abuse is suspected. As such, the escape room balanced a structure-ensured by the facilitator and the design and script of the room-with the flexibility needed to provide a safe space for players to speculate and learn about their strategies and responses to a given scenario.

\subsubsection{Meaningful Staging and Theatrical Environment}

Boal (2002) states that forum theatre "sets" be made within the context of the material constraints of the community creating the event. Every object speaks and communicates the character and the situation of oppression being depicted to the 'spectactors'. As he writes:

Oppression is reflected in clothes, in things. Objects and dress should be real, charged, clear, stimulating. The more care is taken over the aesthetics of the show, the more it will stimulate and the more the audience will take part" (2002, p. 263).

This concern for the aesthetics of the show converges with the need to be mindful of the aesthetics of the room and a concern for focusing on environmental storytelling (Boal 2002) to convey a fuller narrative. When designing Sandra's Keys, we were mindful that oppression and abuse could be reflected in 'things'. We sought to build a space that did not replicate stereotypes about aging, or one particular cultural community. For example, a couch, a carpet, a game of chess, a painting, flowers, a cane, notes on the microwave, a telephone and answering machine: all of these were chosen by the design team to convey a protagonist with a rich life that, on the surface, did not seem to be defined by violent abuse. We included objects (or a lack of objects) and relied on them to tell a deeper story about a protagonist. Elements like an empty fridge, hidden cans of food, and empty pill bottles were used as indices of 
mistreatment, as hoarding and lack of food were identified by our partners as signs of physical mistreatment or situations where older adults are left without life necessities. Recognizing that players might not pick up on these indices, we revisited and further contextualized these game pieces in the debrief.

\subsection{Challenging Dominant Frames}

Our approach to building a social justice game sought to resist and challenge normative societal orders. In fact, the decision to build an escape room on elder abuse was in itself an effort to playfully counter social expectations related to abuse and age, and to garner public interest. Communicating mistreatment and abuse through the contemporary medium of an escape room follows the activist tradition of harnessing culturally resonant symbols to promote social justice ideals (Tarrow 1998). With an understanding that activist tactics need to be attuned to new forms of communications emerging in societies in order to connect with people from different locations, generations and backgrounds (Bogad 2016, pp. 85-86), Sandra's Keys draws upon an activity that has garnered significant cultural currency among younger demographics, to create conversation on issues for older adults in a provocative manner.

We determined that an escape room on elder abuse would be commensurate with our activist goals to engage with the public on a social issue and garner public attention. When we told our colleagues about a plan to devise an escape room on elder abuse, they often reacted with surprise or puzzlement. We suspected that this was a good sign. As we know from past experience, the public and the media are often intrigued by activities that are seen as 'contemporary' when they are led by older adults or deal with issues related to old age (Sawchuk and Lafontaine 2018; Sawchuk 2009). We had collaborated with RECAA, a few years prior, to produce a video of 'flash mob' in a local mall for World Elder Abuse Awareness Day (Grenier and Sawchuk 2017). An escape room on elder abuse echoed this pattern of older adults co-opting events that focus on younger generations and challenging cultural expectations of 'appropriate' behaviours for seniors.

Kevin Michael DeLuca's (1999) writing on rhetoric and activism conceptualizes these activist actions that challenge and contradict the logics that are upheld by socially-established orders, and refers to them as 'image events'. Harnessing and representing social contradictions can not only open up different ways of thinking about a topic but can also break from expected frames of representation and propel social issues to the fore of the public agenda. There were two elements of contradiction inherent to the idea of an escape room on elder abuse. First, there is a juxtaposition of a ludic and typically commercial genre with a serious social issue, which makes the uneasy suggestion that the difficult and often invisible situations of oppression lived by some individuals in society can be better understood by playing a game. Second there is a juxtaposition of a contemporary and trendy genre of interactive games, which is typically targeted at younger audiences (Nicholson 2016), being co-designed by older adults and representing an issue associated with old age.

Both of these juxtapositions made Sandra's Keys stand out within the activities organized at the community event we organized, and fostered local public interest. 
As well, the escape room garnered significant interest from local media. Sandra's Keys became an opportunity for the activists of RECAA to be interviewed by journalists, and beyond the initial questions about the escape room from reporters, they were able to steer the conversation to elder abuse-a subject seldom adequately covered in mainstream media (Beard and Payne 2005; Faccinetti 2004).

\section{Confronting Limitations}

We initially intended the escape room on elder abuse to be played by diverse groups-but we especially wanted older adults to play. Yet we found that we had limited success in reaching our originally-intended audience. Instead, our room was appealing to two groups of people. On the one hand, people who work in the social services and healthcare centre were intrigued by the project and its ability to reach the public, and wanted to experience the game first-hand. On the other hand, our more enthusiastic participants were in fact young adults-often students-who were drawn to the idea of playing a free escape room at a convenient location for them. We sometimes had difficulty explaining the genre to the older adults who had never partaken in an escape room. The term 'escape' alongside commercial presentations of rooms made some seniors hesitant because they thought that the game was a 'brain test'. Others queried whether it was an inappropriate format to discuss elder abuse. We approached these hesitations through conversation, explaining the format of escape rooms, the project, the motivation of its design team and the purpose of the activity. While many of these efforts were successful, the initial experience in building an escape room on elder abuse made us realize that the genre and the premise of the project resonated most strongly with a younger population. Our colleague from CREGÉS helped put this 'failure' into perspective and noted that this was in fact a unique opportunity to reach a demographic group that was seldom-if ever-the target of sensitization efforts pertaining to elder abuse. In a future iteration of the project, we will undertake semi-structured interviews with players and set up Sandra's Keys in a local libraries and community centres. Through collaboration with university and college faculty and administrators, we will specifically target young adults as players and engage in a more detailed analysis of player repsonses to the game.

\section{Conclusion}

In conclusion, forum theatre, when understood as a set of practices designed to engage with the diverse publics of various classes and education levels in non-hierarchical ways, has helped us to understand the potential of contemporary escape rooms to engage with a wide range of audiences on serious matters with societal resonance. It also has assisted us in developing the potential place of social justice not just as an idea, but as a part of one's design practice, within the games studies literature. While social impact games and social justice games both share the goal of creating social transformation, we have introduced the term 'social justice game' 
to assert the connections between activism, social justice and games studies, which was embedded in our objectives as activist game designers in three ways. First, by implementing a design process grounded in PAR Sandra's Keys consolidated existing relationships between the members of the design team around a common social justice goal. This partnership and commitment deliberately brought activist practices to the design process. The PAR approach allowed for a socially-engaged game to be built from a shared activist goal. Second, Sandra's Keys emphasizes the potential of games to exist as potent and contemporary tools in the 'arsenal' of communitybased activism. As we have learned from this co-design experience, escape rooms can imaginatively deploy long-standing activist practices, such as those of forum theatre and reach unlikely audiences. Third, the escape room we designed sought to playfully contradict dominant societal norms related to age. It did so by framing an issue related to later life through a medium associated with youth, thus challenging expectations of age-appropriate behaviours and interests. Sandra's Keys was an outcome of a deliberate commitment to activist goals shared across the community, social service and university sectors, and an understanding that lasting societal change is seldom immediate, and requires sustained, creative action.

Open Access This article is licensed under a Creative Commons Attribution 4.0 International License, which permits use, sharing, adaptation, distribution and reproduction in any medium or format, as long as you give appropriate credit to the original author(s) and the source, provide a link to the Creative Commons licence, and indicate if changes were made. The images or other third party material in this article are included in the article's Creative Commons licence, unless indicated otherwise in a credit line to the material. If material is not included in the article's Creative Commons licence and your intended use is not permitted by statutory regulation or exceeds the permitted use, you will need to obtain permission directly from the copyright holder. To view a copy of this licence, visit http://creativecommons.org/licen ses/by/4.0/.

\section{References}

Adams, V., Burger, S., Crawford, K., \& Setter, R. (2018). Can you escape? Creating an escape room to facilitate active learning. Journal for Nurses in Professional Development. https://doi.org/10.1097/ nnd.0000000000000433.

Baldry, E., \& Mccausland, R. (2009). Mother seeking safe home: Aboriginal women post-release. Current Issues in Criminal Justice, 21, 288-301.

Baum, F., MacDougall, C., \& Smith, D. (2006). Participatory action research. Journal of Epidemiology and Community Health, 60(10), 854-857. https://doi.org/10.1136/jech.2004.028662.

Beard, H., \& Payne, B. K. (2005). The portrayal of elder abuse in the national media. American Journal of Criminal Justice, 29, 269-284.

Blocker, K. A., Wright, T. J., \& Boot, W. R. (2014). Gaming preferences of aging generations. Gerontechnology. International Journal on the Fundamental Aspects of Technology to Serve the Ageing Society, 12(3), 174-184.

Boal, A. (2002). Games for Actors and Non-actors. London: Psychology Press.

Boal, A. (2005). Theatre of the Oppressed (30th Anniversary Ed., M. Bergman Ramos, Trans.), Continuum, New York.

Bogad, L. M. (2016). Tactical Performance: The Theory and Practice of Serious Play (1st ed.). New York: Routledge.

Boshci, M. (2016). The escape room. Training, 66-88.

CBC. (2017). Escape Room Shows Some of the Challenges Homeless People Face. Retrieved from https ://www.cbc.ca/player/play/1063935043981. 
Consalvo, M., \& Begy, J. (2015). Players and their pets: Gaming communities from beta to sunset. Minneapolis: University of Minnesota Press.

De Schutter, B. (2019). Brukel. Retrieved from https://www.bobdeschutter.be/brukel.

DeHart, D., Webb, J., \& Cornman, C. (2009). Prevention of elder mistreatment in nursing homes: competencies for direct-care staff. Journal of Elder Abuse \& Neglect, 21(4), 360-378.

DeLuca, K. M. (1999). Image Politics: The New Rhetoric of Environmental Activism. New York: Guilford Publications.

Ejaz, F. K., Rose, M., \& Anetzberger, G. (2017). Development and implementation of online training modules on abuse, neglect, and exploitation. Journal of Elder Abuse \& Neglect, 29(2-3), 73-101. https://doi.org/10.1080/08946566.2017.1307153.

Eubanks, V. (2012). Digital Dead End: Fighting for Social Justice in the Information Age. Cambridge: MIT Press.

Eukel, H. N., Frenzel, J. E., \& Cernusca, D. (2017). Educational gaming for pharmacy students-design and evaluation of a diabetes-themed escape room. American Journal of Pharmaceutical Education, 81(7), 1-5.

Faccinetti, J. D. (2004). Making strategic communications work to prevent elder abuse. Journal of Elder Abuse \& Neglect, 14(4), 11-20. https://doi.org/10.1300/J084v14n04_03.

Frasca, G. (2001). Rethinking agency and immersion: video games as a means of consciousness-raising. Digital Creativity, 12(3), 167-174.

Fraser, N. (1999). Social justice in the age of identity politics: redistribution, recognition, and participation. Culture and Economy after the Cultural Turn, pp. 25-52 https://doi.org/10.4135/9781446218 112.

Freire, P., \& Macedo, D. (2000). Pedagogy of the Oppressed, 30th Anniversary Edition (30th Anniversary edition; M. B. Ramos, Trans.), New York, Continuum.

Grace, L. (2019). Doing Things with Games: Social Impact Through Play (1st ed.). Boca Raton: Routledge.

Grenier, L., \& Sawchuk, K. (2017). Regards croisés sur une mobilisation éclair: À-propos de la médiatisation et du vieillissement. Recherches Sociographique, 58(1), 93-117.

Guruge, S., Sidani, S., Matsuoka, A., Man, G., \& Pirner, D. (2019). Developing a comprehensive understanding of elder abuse prevention in immigrant communities: a comparative mixed methods study protocol. British Medical Journal Open. https://doi.org/10.1136/bmjopen-2018-022736.

Harbinson, J. (1999). Models of intervention for "elder abuse and neglect": A Canadian perspective on ageism, participation, and empowerment. Journal of Elder Abuse \& Neglect, 10(3-4), 1-17. https:// doi.org/10.1300/J084v10n03_01.

Hearn, G., Tacchi, J., Foth, M., \& Lennie, J. (2009). Action research and new media: Concepts, methods, and cases. Cresskill, NJ: Hampton Press.

Hermanns, M., Deal, B., C, A., Hillhouse, S., Opella, J., Faigle, C., \& Campbell, R. (2017). Using an "escape room" toolbox approach to enhance pharmacology education. Nursing Faculty Publications and Presentations. Retrieved from https://scholarworks.uttyler.edu/nursing_fac/16.

It's not right. (2020). Retrieved from http://itsnotright.ca/.

Joshi, S., \& Flaherty, J. H. (2005). Elder abuse and neglect in long-term care. Clinics in Geriatric Medicine, 21(2), 333-354. https://doi.org/10.1016/j.cger.2004.10.009.

Khaled, R., Vasalou, A., Van Mechelen, M., \& Vanden Abeele, V. (2014). Participatory Design for Serious Game Design: Truth and Lies. https://doi.org/10.1145/2658537.2659018.

La Presse Canadienne. (2018). Laval: Un jeu d'évasion immersif pour prévenir la violence amoureuse. Radio-Canada.ca. Retrieved from https://ici.radio-canada.ca/nouvelle/1138622/preven-quete-jeulaval-prevention-violence-amoureuse.

Lafontaine, C, \& Sawchuk, K. (2018). Promising practices in collaborative digital literacy and digital media-making with older adults. In Human Aspects of IT for the Aged Population. Acceptance, Communication and Participation (pp. 492-504). Switzerland: Springer.

Lama, A. (2018). Millennial leisure and tourism: The rise of escape rooms. Cuadernos de Turismo, 41, 615-636. https://doi.org/10.6018/turismo.41.327181.

LaPensée, E. (2014). Survivance among social impact games. Loading, 8(13). Retrieved from http://journ als.sfu.ca/loading/index.php/loading/article/view/141.

Lee, Y.-S., Moon, A., \& Gomez, C. (2014). Elder mistreatment, culture, and help-seeking: a cross-cultural comparison of older Chinese and Korean immigrants. Journal of Elder Abuse \& Neglect, 26, 244-269. https://doi.org/10.1080/08946566.2013.820656. 
Loos, E. (2014). Designing meaningful intergenerational digital games. In: International Conference on Communication, Media, Technology and Design. Presented at the International Conference on Communication, Media, Technology and Design, Instanbul.

Lugmayr, A., Sutinen, E., Suhonen, J., Sedano, C. I., Hlavacs, H., \& Montero, C. S. (2017). Serious storytelling-a first definition and review. Multimedia Tools and Applications, 76(14), 15707-15733. https://doi.org/10.1007/s11042-016-3865-5.

Marston, H. R. (2013). Design recommendations for digital game design within an ageing society. Educational Gerontology, 39, 103-118. https://doi.org/10.1080/03601277.2012.689936.

McCool, J. J., Jogerst, G. J., Daly, J. M., \& Xu, Y. (2009). Multidisciplinary reports of nursing home mistreatment. Journal of the American Medical Directors Association, 10(3), 174-180. https://doi. org/10.1016/j.jamda.2008.09.005.

Nicholson, S. (2015). Peeking behind the locked door: A survey of escape room facilities. White Paper available at http://scottnicholson.com/pubs/erfacwhite.pdf.

Nicholson, S. (2016). The State of Escape: Escape Room Design and Facilities (Vol. 20, p. 20). Lansing: Michigan.

Osmanovic, S., \& Pecchioni, L. (2016). Beyond entertainment: motivations and outcomes of video game playing by older adults and their younger family members. Games and Culture, 11, 130-149. https ://doi.org/10.1177/1555412015602819.

Patrick, M., Chan, W. Y. A., Tiflati, H., \& Reid, E. (2019). Religion and Secularism: Four Myths and Bill 21. Toronto: Canadian Race Relations Foundation.

Podnieks, E., \& Thomas, C. (2017). The consequences of elder abuse. In X. Dong (Ed.), Elder Abuse: Research, Practice and Policy (pp. 109-123). Cham: Springer.

Reason, P., \& Bradbury, H. (2008). The Sage Handbook of Action Research. Thousand Oaks: Sage.

Rodríguez, M. A., Wallace, S. P., Woolf, N. H., \& Mangione, C. M. (2006). Mandatory reporting of elder abuse: Between a rock and a hard place. The Annals of Family Medicine, 4(5), 403-409. https://doi. org/10.1370/afm.575.

Romero, M., \& Lille, B. (2017). Intergenerational techno-creative activities in a library fablab. In J. Zhou \& G. Salvendy (Eds.), Human Aspects of IT for the Aged Population. Applications, Services and Contexts (pp. 526-536). Berlin: Springer.

Ruggiero, D. (2015). The effect of a persuasive social impact game on affective learning and attitude. Computers in Human Behavior, 45, 213-221. https://doi.org/10.1016/j.chb.2014.11.062.

Sawchuk, D. (2009). The raging grannies: Defying stereotypes and embracing aging through activism. Journal of Women \& Aging, 21, 171-185. https://doi.org/10.1080/08952840903054898.

Sawchuk, K. (2013). Tactical mediatization and activist ageing: Pressures, push-backs, and the story of RECAA, MedieKultur: Journal of Media and Communication Research, 29(54). https://doi. org/10.7146/mediekultur.v29i54.7313.

Sawchuk, K., \& Lafontaine, C. (2018). Activist aging: The tactical theatrics of RECAA. In M. Chazan, M. Baldwin, \& P. Evans (Eds.), Unsettling Activisms: Critical Interventions on Aging, Gender and Social Change (pp. 50-65). Toronto: Women's press.

Sayago, S. (2019). Perspectives on human-computer interaction research with older people. Switzerland: Springer International Publishing.

Shyba, L. (2008). Beyond Fun and Games: Interactive Theatre and Serious Videogames with Social Impact. Saarbrücken: VDM Verlag.

Susi, T., Johannesson, M., \& Backlund, P. (2007). Serious games-an overview. Technical report HS1k1-TR-07-001. Sweden: School of Humanities and Informatics, University of Skovde.

Swain, C. (2007). Designing games to effect social change. In DiGRA Conference.

Tarrow, S. (1998). Power in Movement: Social Movements and Contentious Politics. Cambridge: Cambridge University Press.

The National Seniors Council. (2007). Report of the National Seniors Council of Elder Abuse (p. 24) [Government]. Retrieved from National Seniors Council website: https://www.canada.ca/content/ $\mathrm{dam} / \mathrm{nsc}$-cna/documents/pdf/policy-and-program-development/publications-reports/2007/elder -abuse-report/elder-abuse-report-en.pdf.

Vörös, A. I. V., \& Sárközi, Z. (2017). Physics escape room as an educational tool. AIP Conference Proceedings, 1916(1), 050002. https://doi.org/10.1063/1.5017455.

Walsh, C. A., Ploeg, J., Lohfeld, L., Horne, J., MacMillan, H., \& Lai, D. (2007). Violence across the lifespan: Interconnections among forms of abuse as described by marginalized Canadian elders and their care-givers. British Journal of Social Work, 37, 491-514. https://doi.org/10.1093/bjsw/bcm02 2 . 
Xie, B., Druin, A., Fails, J., Massey, S., Golub, E., Franckel, S., et al. (2012). Connecting generations: Developing co-design methods for older adults and children. Behaviour \& Information Technology, 31(4), 413-423. https://doi.org/10.1080/01449291003793793. 